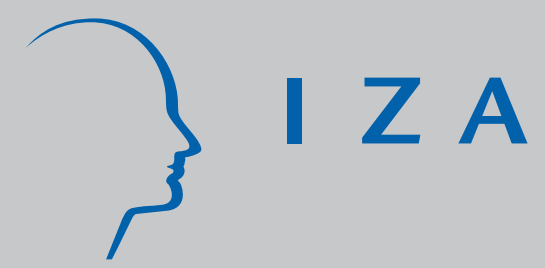

IZA DP No. 7510

Neighbourhood Effects on Migrant Youth's Educational Commitments: An Enquiry into Personality Differences

Jaap Nieuwenhuis

Pieter Hooimeijer

Maarten van Ham

Wim Meeus

July 2013 


\title{
Neighbourhood Effects on Migrant Youth's Educational Commitments: An Enquiry into Personality Differences
}

\author{
Jaap Nieuwenhuis \\ Utrecht University
}

Pieter Hooimeijer

Utrecht University

Maarten van Ham

Delft University of Technology and IZA

Wim Meeus

Utrecht University and Tilburg University

Discussion Paper No. 7510

July 2013

IZA

P.O. Box 7240

53072 Bonn

Germany

Phone: +49-228-3894-0

Fax: +49-228-3894-180

E-mail: iza@iza.org

Any opinions expressed here are those of the author(s) and not those of IZA. Research published in this series may include views on policy, but the institute itself takes no institutional policy positions. The IZA research network is committed to the IZA Guiding Principles of Research Integrity.

The Institute for the Study of Labor (IZA) in Bonn is a local and virtual international research center and a place of communication between science, politics and business. IZA is an independent nonprofit organization supported by Deutsche Post Foundation. The center is associated with the University of Bonn and offers a stimulating research environment through its international network, workshops and conferences, data service, project support, research visits and doctoral program. IZA engages in (i) original and internationally competitive research in all fields of labor economics, (ii) development of policy concepts, and (iii) dissemination of research results and concepts to the interested public.

IZA Discussion Papers often represent preliminary work and are circulated to encourage discussion. Citation of such a paper should account for its provisional character. A revised version may be available directly from the author. 


\section{ABSTRACT \\ Neighbourhood Effects on Migrant Youth's Educational Commitments: An Enquiry into Personality Differences}

In the neighbourhood effects literature, the socialisation mechanism is usually investigated by looking at the association between neighbourhood characteristics and educational attainment. The step in between, that adolescents actually internalise educational norms held by residents, is often assumed. We attempt to fill this gap by looking at how educational commitments are influenced by neighbourhood characteristics. We investigate this process for migrant youth, a group that lags behind in educational attainment compared to native youth, and might therefore be particularly vulnerable to neighbourhood effects. To test our hypothesis we used longitudinal panel data with five waves $(N=4179)$, combined with fixedeffects models which control for a large portion of potential selection bias. These models have an advantage over naïve OLS models in that they predict the effect of change in neighbourhood characteristics on change in educational commitment, and therefore offer a more dynamic approach to modelling neighbourhood effects. Our results show that living in neighbourhoods with higher proportions of immigrants increases the educational commitments of migrant youth compared to living in neighbourhoods with lower proportions. Besides, we find that adolescents with a resilient personality experience less influence of the neighbourhood context on educational commitments than do adolescents with other personalities.

JEL Classification: I24, J15, R23

Keywords: neighbourhood effects, educational commitment, adolescents, personality, migrant youth, fixed effects

Corresponding author:

Jaap Nieuwenhuis

Urban and Regional research centre Utrecht (URU)

Faculty of Geosciences

Utrecht University

P.O. box 80115

3508 TC Utrecht

The Netherlands

E-mail: j.g.nieuwenhuis@uu.nl 


\section{Introduction}

Research investigating educational attitudes found that there is a gap between educational attitudes and achievement for migrant youth: migrant youth seem to have similar or more positive educational attitudes compared to native youth, however, the educational achievements of migrant youth still lags behind in adolescence. This was found in countries as different as the Netherlands (Elffers \& Oort, 2013) and the US (Downey et al., 2009). Studies have showed that educational attitudes are related to better school performance (Germeijs \& Verschueren, 2007; Klimstra et al., 2012; Robbins et al., 2004), however, the relation might be different for migrant and native youth. The fact that migrant youth's educational attitudes are on a par with those of native youth, suggests that migrant youth experience obstacles to educational success not experienced to the same extent by native youth. One explanation for their lower educational achievement might be that migrant parents often have a low socio-economic status, and therefore have a low likelihood to provide their children the economic and cultural resources, including cultural and linguistic competences, to succeed in the educational system (Bourdieu, 1986; Coleman, 1988; Lareau, 2003).

Another explanation is that there are contextual factors in the residential environment (so-called neighbourhood effects) which may affect the educational outcomes of migrant youth (for an overview of the neighbourhood effects literature see: Ellen \& Turner, 1997; Galster, 2002; Dietz, 2002; Durlauf, 2004; van Ham et al., 2012; 2013). There is substantial debate with little apparent agreement on the causal mechanisms which produce neighbourhood effects, and their relative importance in shaping individuals' life chances compared to other influences (van Ham et al., 2012). Most studies of neighbourhood effects only look at the relationship between the neighbourhood context and educational outcomes, including final grades, graduation, and highest achieved education (for reviews, see: Leventhal \& Brooks-Gunn, 2000; Nieuwenhuis \& Hooimeijer, 2013). Another strand of research investigates outcomes that may affect educational achievement, such as internalising and externalising behaviour problems, depression, delinquency, and substance abuse (Leventhal \& Brooks-Gunn, 2000). However, most studies seem to ignore the link between these two strands: the role of educational commitment and how it is influenced by the neighbourhood context.

The neighbourhood context might influence educational outcomes through processes of socialisation, where neighbourhood residents hold certain norms and transmit these norms to other residents. A high presence of positive attitudes towards education in neighbourhoods can be expected to reflect positively on adolescents. Adolescents are more inclined to adopt positive attitudes when they have positive role models showing the merits of education (Ainsworth, 2002; Wilson, 1996), and when there is more adult interference and social control in cases such as truancy (Akers et al., 1979; Galster, 2011; Sampson \& Raudenbush, 1999). The neighbourhood effects thesis suggests that because of the presence of certain norms in the neighbourhood, adolescents will internalise these norms, which consequently has an effect on their educational achievement.

One of the main problems in the neighbourhood effects literature is that the outcomes of empirical studies into neighbourhood effects are biased by unmeasured characteristics of individuals: unobserved heterogeneity in research samples obscures 'true' neighbourhood 
effects. In this paper we argue that that personality might be such a commonly unobserved individual trait that can affect the measured outcomes of neighbourhood effect studies. In a previous study on educational achievement we found that adolescents with a resilient personality are better able to cope with neighbourhood adversity, and therefore less likely to be affected by neighbourhood characteristics than adolescents with a less resilient personality (Nieuwenhuis et al., 2013). In the current study we will investigate to what extent adolescents' personality influences the strength of the neighbourhood effect on educational commitments. We hypothesise that adolescents with a resilient personality are better able to cope with neighbourhood adversity, and will therefore experience less influence of neighbourhood characteristics on their educational commitment than adolescents with other personalities.

We want to note that selection bias is a problem for most neighbourhood research. Neighbourhoods are not random selections of households, but families sort into neighbourhoods according to their preferences and economic constraints. When studies do not properly control for this problem, found neighbourhood effects could be overestimated or underestimated. Therefore, to test our hypothesis we used longitudinal panel data consisting of five waves ( $\mathrm{N}=4179$ ), which enables us to use fixed-effects models, which take care of time-invariant unobserved variables that have the potential to cause selection bias (Allison, 2009).

\section{Theory}

To study neighbourhood effects on migrant youth's educational commitments, we develop hypotheses for two neighbourhood characteristics: the degree of immigrant concentration in neighbourhoods and neighbourhood affluence. Then, we will elaborate on how having a resilient personality may alter the relationship between neighbourhood characteristics and educational commitments.

\section{Immigrant concentrations}

A high proportion of non-western immigrants in a neighbourhood is often considered as undesirable by local and national governments because it can hinder the integration of immigrants in the host society. It can be argued that, for residents with an immigration background, contacts with natives are more beneficial than contacts with co-ethnics, since natives have in general better knowledge about, for example, jobs and the educational system, and therefore can provide access to the host society (Burt, 2000; Putnam, 2000). People's social networks are often influenced by the composition of their environment (Mollenhorst et al., 2008). It was found that, in the Netherlands, immigrants living in neighbourhoods with a higher proportion of immigrants have a lower likelihood to include Dutch people in their social network (Martinovic et al., 2009). A high proportion of immigrants in the neighbourhood is to some extent a proxy for neighbourhood disadvantage, since immigrants are lower educated, have more unemployment, earn less, and are less satisfied with their living environment compared to native Dutch residents (Gijsberts et al., 2012). This suggests that immigrants living in ethnically concentrated neighbourhoods are more likely to lack the social capital which would enable them to succeed in the educational system. Such 
neighbourhoods will provide adolescents with less knowledge about the educational system and with less positive role-models, showing them the benefits of education for upward social mobility (Ainsworth, 2002). This may lead to negative attitudes towards education, because the importance of education for upward social mobility is not recognised (MacLeod, 1987).

Looking at it from another perspective, higher concentrations of immigrants might also be beneficial for migrant youth, when shared positive attitudes towards education are combined with a strong co-ethnic social network. First generation immigrants are a group that abandoned their home country to build a life in a new country. For this group, migration is likely to be a strong incentive to perform well in the host country and make use of the available opportunities (Pásztor, 2010). However, many first generation immigrants experience difficulties in overcoming their disadvantaged situation. When immigrants experience difficulties in their own lives to get ahead, they may focus on stimulating the educational success of their children, that way trying to achieve intergenerational social mobility (Zhou \& Bankston, 1998). In neighbourhoods with higher shares of immigrants, the likelihood to meet co-ethnics increases. This can give rise to ethnic social networks and institutions, which may help solve education-specific problems and share information; reinforce common norms about education; and offer help in monitoring each other's children (Portes \& MacLeod, 1999; Zhou, 2009). Combining the arguments above would mean that in neighbourhoods with higher proportions of immigrants, the likelihood is higher for the presence of strong ethnic social networks which share the norm that stimulating their children to succeed in host country's educational system is important. And, because of more social closure, adult residents are better able to enforce these norms, leading to a higher likelihood for migrant youth to internalise these norms.

Because two opposing ideas exist about how the neighbourhood's immigrant concentration affects its migrant youth's educational commitments, we will examine which mechanism is supported by our results.

\section{Neighbourhood affluence}

Neighbourhoods with higher levels of affluence, as compared to those with higher levels of poverty, are expected to be better environments for youth to grow up. More affluent neighbourhoods often have higher levels of employed and higher educated residents, that way providing adolescents with more positive role-models who demonstrate the advantages of education. Adolescents growing up in more affluent neighbourhoods are therefore more likely to incorporate positive attitudes towards education (Ainsworth, 2002; Wilson, 1996). Besides, more residents are higher educated in affluent neighbourhoods and therefore more likely to understand the importance of education. As residents of more affluent neighbourhoods are often better able to enforce common norms (Sampson \& Raudenbush, 1999), they may also be more likely to instil positive educational attitudes in neighbourhood adolescents. We suspect that adolescents growing up in more affluent neighbourhoods will develop stronger educational commitments because of the presence of more positive rolemodels and a stronger sanctioning mechanism of neighbourhood adults. Inversely, adolescent growing up in poverty neighbourhoods will develop weaker educational commitments because of the absence of these characteristics. 


\section{Resilient personalities}

In the introduction we argued that personality might be a commonly unobserved personal trait that can affect the relationship between neighbourhood characteristics and educational commitment. Previous studies already suggested that there is a relationship between neighbourhood effects and personality traits. For example, studies have found different effects of impulsivity on delinquency between neighbourhoods scoring high and low on indicators for disadvantage (Lynam et al., 2000; Meier et al., 2008; Zimmerman, 2010). Furthermore, neighbourhood characteristics have found to moderate the effects of low selfcontrol on violent victimisation (Gibson, 2012), of hyperactivity, impulsivity, and attention difficulties on conduct problems (Zalot et al., 2009), and of thrill and adventure seeking and lack of premeditation on offending (Jones \& Lynam, 2009). In studies on the relationship between the neighbourhood and educational outcomes, personality has however not been introduced yet. Besides, studies thus far have relied on personality traits, while we employ a person-centred approach, using personality types.

Personality research offers a useful distinction of three personality types that score differently on ego-control and ego-resiliency: resilients, undercontrollers, and overcontrollers (Block \& Block, 1980). Ego-control is defined as the tendency to contain versus express emotional and motivational impulses, and ego-resiliency as the tendency to respond flexibly versus rigidly to environmental demands (Klimstra et al. 2010; Meeus et al. 2011). Resilients are characterised by medium levels of ego-control and high level of ego-resiliency. Undercontrollers score low and overcontrollers high on ego-control, however, both score low on ego-resiliency (Asendorpf et al. 2001; Caspi 1998). Resilients are the best adjusted group and are likely to most effectively cope with neighbourhood influences, because they can respond flexibly and adaptively to environmental demands.

Above, we argued that low levels of neighbourhood affluence and high levels of immigrants in the neighbourhood (as a proxy for neighbourhood disadvantage) might have a negative impact on the development of migrant youth's educational commitments. This means that neighbourhoods with these characteristics can be described as more stressful and demanding environments, where adolescents are at higher risk to be affected negatively. We hypothesise that the negative influence of neighbourhood disadvantage on adolescents' educational commitments is weaker for resilients than for overcontrollers and undercontrollers.

\section{Data and methods}

Data

Our individual-level data are drawn from the Conflict and Management of Relationships (Conamore) dataset. The Conamore is a panel dataset consisting of 1,313 respondents recruited from twelve high schools in the province of Utrecht, the Netherlands. The dataset consists of two cohorts: early-to-middle adolescents ( $n=923 ; 70.3 \%)$ who were on average 12.4 years of age at the first wave, and middle-to-late adolescents ( $n=390 ; 29.7 \%)$ with an average age of 16.7 years at the first wave. The first wave was collected in 2001/'02, and waves 1 through 5 were collected with a one year interval, with the data collection of wave 5 
in 2005/'06. The sixth wave from 2009/'10 included an additional Life History Calendar (LHC) with retrospective questions from the age of 12 until the timing of the sixth wave. In waves 1, 2, 3, 4, 5 and 6 the number of respondents was 1,313, 1,313, 1,293, 1,292, 1,275, and 1,026 , respectively. For the first five waves, sample attrition was very low $(1.2 \%$ across waves). Attrition for the sixth wave is bigger (20\%), because of the larger time gap between wave five and six, compared to the one-year gap between the earlier waves. For our analyses we use wave 1 through 5 and the LHC. After listwise deletion of cases with missing values, our sample consists of 895 respondents, of which 801 are natives and 94 are migrant youth. We restricted the analyses to respondents who have at least two observations in different waves. The final $\mathrm{N}$ is 4179 (total observations across waves for the 895 respondents), of which 3750 for natives and 429 for migrant youth.

Because the Conamore data is geo-coded, and includes all six-digit postcodes (areas containing, on average, 17 households) where respondents lived from the age of twelve onwards, we are able to enrich the data with neighbourhood characteristics on the postcodelevel as provided by Statistics Netherlands (CBS, 2006, 2011).

\section{Measurements}

The dependent variable is identification with educational commitments, which is measured using the Utrecht-Management of Identity Commitments Scale (U-MICS; Crocetti et al. 2008), which consists of five items to measure the degree to which adolescents derive selfconfidence from the education choices they made, with response categories 1 (completely untrue) to 5 (completely true). The items are (translated from Dutch): "My education makes me feel confident about myself"; "My education gives me certainty in life”; "Because of my education I feel certain about myself”; "My education gives certainty for the future"; and "Because of my education I can perceive the future optimistically". We constructed scales for educational commitment for the five waves, which all had high reliability (Cronbach's $\alpha$ s .90.93). The variable is standardised. Descriptive results for this and other variables can be found in Table 1.

We use two neighbourhood-level independent variables: proportion of non-Western immigrants measured for 2010 and average property value measured for 2004. Both measures are measured on a six-digit postcode scale, which pertains to, on average, 17 households. Sixdigit postcode areas are a good scale to measure socialization hypotheses, because socialization is more likely to happen through neighbours in close proximity than through neighbours living a few blocks away. When respondents change postcode between waves, this is reflected in different values for the two variables in different waves. The proportion of non-Western immigrants is divided into three dummies: $<.10, .10-.20$, and $>.20$, to allow for the measurement of non-linear effects. The average property value is standardised, and is a proxy for neighbourhood affluence.

From the Big Five personality dimensions we constructed three personality types: resilients, overcontrollers, and undercontrollers. The Big Five were measured with a shortened Dutch version of the Big Five questionnaire (Gerris et al., 1998; Goldberg, 1992), containing 30 items, such as: talkative (extraversion), sympathetic (agreeableness), systematic (conscientiousness), worried (emotional stability, reverse coded) and creative (openness to experience). The response categories were 1 (completely true) to 7 (completely 
untrue). We assessed personality at the first wave in order to have a fixed value for our interaction effects. Cronbach's $\alpha$ s for the Big five scales ranged from .77 to .87 . We used Latent Class Analysis (LCA) to detect latent classes of the most typical configurations of the five personality dimension within persons. The distribution of personality dimensions across different personality types we found corresponds to earlier research (Klimstra et al., 2010; Robins et al., 1996). Resilients score high on all five personality dimensions, and highest on extraversion, conscientiousness, emotional stability, and openness to experience. Overcontrollers score highest on agreeableness, but lowest on extraversion and emotional stability. Undercontrollers score lowest on agreeableness and conscientiousness. Our interest lies in resilients' high levels of ego-resiliency versus the low levels of overcontrollers and undercontrollers, so we collapsed overcontrollers and undercontrollers in one category, and created a dummy measuring a resilient personality $(1 ; n=385)$ or a non-resilient personality $(0$; $\mathrm{n}=510)$.

We control for the time-invariant variables age, gender, and parental education. Furthermore, we control for the time-varying variables: delinquency, family structure, educational level, conflict frequency with parents, parental support, and parental power. Age is measured in years and controls for the use of different cohorts. Gender is coded as male (0) and female (1). Parental education is measured in a set of six dummy variables, including: 1) lower vocational education or lower; 2) preparatory middle-level vocational education; 3) middle-level vocational education; 4) higher general continued education or preparatory scientific education; 5) higher vocational education; and 6) scientific education.

The first time-varying variable, delinquency, is measured with 16 items about how often the respondent was involved in certain types of delinquent behaviour in the past twelve months, with the following answering categories: 1 (never), 2 (once), 3 (two-three times), 4 (four times or more). Example items are: stole a bicycle, used marihuana or hash, carried a weapon, and arrested by the police. We constructed scales for all five waves, with Cronbach's $\alpha$ s .82-.90.

Family structure is a dummy measuring whether the respondent was not living with both parents (1), for every wave. This includes: living with one parent; living with a parent and a stepparent; living alone; or a different situation. Educational level at every wave is measured with eight dummies: 1) preparatory middle-level vocational education; 2) higher general continued education; 3) preparatory scientific education; 4) middle-level vocational education; 5) higher vocational education; 6) scientific education; 7) different; 8) not in education.

Conflict frequency with parents is measured using a Dutch version of the Interpersonal Conflict Questionnaire, which was reported to have adequate validity (Laursen, 1993). The questionnaire consists of 35 items of potential topics of conflict with five answering: 1 (never) to 5 (often). The adolescents reported separately for their father and mother whether they had conflict about topics such as dates, privacy, behaviour in school, and homework. The Cronbach's $\alpha$ s range from .92 to .95 across waves. We combined the scales for fathers and mothers in one scale measuring conflict with parents.

Parental support and power are both measured using the Network of Relationship Inventory (NRI) (Furman \& Buhrmester, 1985). The NRI has reported adequate validity (Edens, Cavell \& Hughes, 1999). The questions are asked separately about the father and the 
mother and uses answering categories that range from 1 (little or not at all) to 5 (more is not possible). The support scale consists of 12 items from different subscales of the NRI, such as companionship, instrumental aid, intimacy, nurturance, affection, admiration, and reliable alliance. Examples of items are: "Do you share secrets or personal feelings with you father/mother?" and "Does your father/mother appreciate the things you do?" Across waves, the Cronbach's $\alpha$ s range from .87 to .92 . We combined the scales for fathers and mothers in one scale measuring parental support. The power scale consists of 6 items. Examples items are: "How often does your father/mother tell you what to do?" and "To what extent is your father/mother the boss in your relationship?" Low levels on this scale indicate that adolescents perceive the relationship with their father/mother as equally powerful, high scores indicate that adolescents perceive their father/mother as more powerful. The Cronbach's $\alpha$ s range from .81 to .90 across waves. Again, we combined to scales about fathers and mothers to obtain a measurement for parental power.

Table 1: Descriptive statistics

\begin{tabular}{|c|c|c|c|c|c|c|c|c|}
\hline & \multicolumn{4}{|c|}{$\begin{array}{l}\text { Sample: migrant youth } \\
(\mathrm{N}=429)\end{array}$} & \multicolumn{4}{|c|}{ Sample: natives $(\mathrm{N}=3750)$} \\
\hline & Mean & S.D. & Min. & Max. & Mean & S.D. & Min. & Max. \\
\hline \multicolumn{9}{|l|}{ Dependent variable } \\
\hline Education commitment & .17 & 1.16 & -3.75 & 1.66 & -.02 & .96 & -3.75 & 1.66 \\
\hline \multicolumn{9}{|l|}{ Neighbourhood characteristics } \\
\hline Proportion non-Western immigrants: $<.10$ & .14 & .34 & .00 & 1.00 & .76 & .43 & .00 & 1.00 \\
\hline $.10-.20$ & .10 & .30 & .00 & 1.00 & .14 & .34 & .00 & 1.00 \\
\hline$>.20$ & .76 & .42 & .00 & 1.00 & .10 & .31 & .00 & 1.00 \\
\hline Average property value & -.61 & .51 & -1.15 & 1.95 & .15 & 1.05 & -1.25 & 6.63 \\
\hline \multicolumn{9}{|l|}{ Time-varying covariates } \\
\hline Age in years & 15.86 & 2.45 & 12.00 & 24.00 & 15.45 & 2.34 & 11.00 & 23.00 \\
\hline Delinquency & .15 & .28 & .00 & 1.63 & .15 & .31 & .00 & 3.00 \\
\hline Family structure (1=not with both parents) & .25 & .43 & .00 & 1.00 & .19 & .39 & .00 & 1.00 \\
\hline Conflict frequency with parents & .70 & .51 & .00 & 2.41 & .65 & .49 & .00 & 3.08 \\
\hline Parental support & 2.54 & .68 & .00 & 4.00 & 2.50 & .58 & .04 & 4.00 \\
\hline Parental power & 1.67 & .74 & .00 & 4.00 & 1.41 & .61 & .00 & 4.00 \\
\hline \multicolumn{9}{|l|}{ Time-invariant covariates } \\
\hline Resilient personality & .29 & .45 & .00 & 1.00 & .45 & .50 & .00 & 1.00 \\
\hline Gender (1=female) & .58 & .49 & .00 & 1.00 & .56 & .50 & .00 & 1.00 \\
\hline \multicolumn{9}{|l|}{ Parental education ${ }^{\mathrm{a}}$ : Lower vocational } \\
\hline education or less & .32 & .47 & .00 & 1.00 & .12 & .33 & .00 & 1.00 \\
\hline Preparatory middle-level voc. educ. & .27 & .45 & .00 & 1.00 & .19 & .39 & .00 & 1.00 \\
\hline Middle-level vocational education & .22 & .41 & .00 & 1.00 & .19 & .39 & .00 & 1.00 \\
\hline Higher general continued education or & & & & & & & & \\
\hline preparatory scientific education & .17 & .38 & .00 & 1.00 & .22 & .41 & .00 & 1.00 \\
\hline Higher vocational education & .11 & .32 & .00 & 1.00 & .21 & .41 & .00 & 1.00 \\
\hline Scientific education & .15 & .36 & .00 & 1.00 & .34 & .47 & .00 & 1.00 \\
\hline
\end{tabular}

${ }^{\mathrm{a}}$ The sample size for parental education is 406 for the migrant youth sample and 3747 for the native sample.

\section{Method}

Because we have a panel dataset with five observations over five years for all variables, we are able to employ a fixed-effects (FE) model, which controls for any time-invariant unobserved characteristics. This removes potential selection bias emerging from timeinvariant characteristics that influence both neighbourhood selection and educational commitments (Allison, 2009; Galster, 2008). We ran a Hausman test to examine whether a 
fixed-effects model is favoured over a random effects model. The result is that the unique errors are likely correlated with the independent variables, making a fixed-effects model the preferred choice. In the tables we report robust standard errors.

To emphasise the importance of controlling for selection bias, we also employ OLS models and compare the results with the outcomes of the fixed-effects models. In the OLS models we include time-invariant control variables, as well as the same time-varying variables as used in the fixed-effects models. Because within-person observations over time are not independent, we cluster the observations on individuals, thus obtaining more robust standard errors.

We will look at differences between native adolescents and migrant youth (both parents foreign born) by analysing them separately. Next, we will assess our hypothesis that adolescents with a resilient personality experience less influence of the neighbourhood by including an interaction effect between the neighbourhood characteristic 'proportion of nonWestern immigrants' and the variable measuring whether or not the respondent had a resilient personality at the time of wave 1 .

\section{Results}

To test our hypotheses, we conduct analyses for migrant youth, as well as for native adolescents as a comparative sample (Table 2). Comparing migrant youth (Model 1) and native adolescents (Model 3) we immediately find that natives are not influenced by the neighbourhood proportion of non-Western immigrants, while migrant youth clearly are. We can see that, compared to neighbourhoods with less than $10 \%$ non-western immigrants, neighbourhoods with more than $20 \%$ non-Western immigrants increase the educational commitments of migrant youth. However, neighbourhoods with 10-20\% non-Western immigrants have the strongest positive effect on educational commitments. This finding supports the idea that ethnic social capital in neighbourhoods stimulates migrant youth to have stronger educational commitments. Comparing the magnitudes of .10-.20 and >.20 with a Wald test, we find that the difference is marginally significant $(F(1,93)=3.58 ; p=.0616)$. This indicates that neighbourhoods with a certain mix are preferable. Considering the small sample of migrant youth, this is an interesting finding.

To test whether adolescents with a resilient personality are influenced less by the neighbourhood than adolescents with other personalities, we include an interaction in Model 2 between having a resilient personality and the proportion of non-Western immigrants, for the sample of adolescents with an migration background. We find that the positive effect of higher proportions of non-Western immigrants on educational commitments is still positive, but much weaker for resilients compared to adolescents with other personalities. The effect magnitude for other personalities is reflected in the main effect of proportion of non-Western immigrants, which has, compared to the model without interactions (Table 2: M1), increased. This supports our hypothesis that adolescents with a resilient personality experience weaker neighbourhood effects compared to adolescents with another personality type. 
Table 2: FE models on educational commitments: comparison of natives and migrant youth.

\begin{tabular}{llll}
\hline & $\begin{array}{l}\text { M1: sample: } \\
\text { migrant youth }\end{array}$ & $\begin{array}{l}\text { M2: M1 }+ \\
\text { interaction }\end{array}$ & $\begin{array}{l}\text { M3: sample: } \\
\text { natives }\end{array}$ \\
\hline $\begin{array}{l}\text { Neighbourhood characteristics } \\
\text { Proportion non-Western immigrants (ref.: }<.10)\end{array}$ & coef. (s.e.) & coef. (s.e.) & (s.e.) \\
$\quad 10-.20$ & $1.442(.417)^{* *}$ & $2.028(.370)^{* *}$ & $-.115(.126)$ \\
$\quad>.20$ & $.940(.346)^{* *}$ & $1.517(.193)^{* *}$ & $-.086(.115)$ \\
Prop. n.-W. im. .10.-20*resilient personality & & $-.988(.535) \dagger$ & \\
Prop. n.-W. im. $>.20 *$ resilient personality & & $-.956(.247)^{* *}$ & \\
Average property value & $-.215(.182)$ & $-.206(.188)$ & $.002(.040)$ \\
Individual characteristics & & & \\
Age in years & $-.079(.038)^{*}$ & $-.076(.039) \dagger$ & $.051(.011)^{* *}$ \\
Delinquency & $-.293(.255)$ & $-.297(.254)$ & $.026(.098)$ \\
Family structure (not with both parents) & $.038(.239)$ & $.034(.244)$ & $-.052(.067)$ \\
Conflict frequency with parents & $-.293(.155) \dagger$ & $-.291(.155) \dagger$ & $-.048(.051)$ \\
Parental support & $.288(.109)^{*}$ & $.282(.111)^{*}$ & $.322(.046)^{* *}$ \\
Parental power & $-.074(.103)$ & $-.074(.103)$ & $-.161(.042)^{* *}$ \\
Intercept & $.063(.697)$ & $-.237(.676)$ & $-1.317(.237)^{* *}$ \\
$\mathrm{R}^{2}$ & .1010 & .0536 & .0418 \\
$\mathrm{~F}$ & $4.88 * *$ & & $11.966^{* *}$ \\
$\mathrm{~N}$ & 429 & 429 & 3750
\end{tabular}

The average property value is insignificant, both in the migrant and in the native model. For migrant youth, apparently, the demographic composition of the neighbourhood is more important than neighbourhood wealth. We cannot support the hypothesis that more affluent neighbourhoods provide a better environment for migrant youth's development of educational commitments. Furthermore, age seems to be of importance, albeit working in a different direction for native and migrant youth. The variables on the relationship with parents seem to have logical directions: more conflict leads to less educational commitments (for migrant youth); more parental support leads to more educational commitments; and more parental power leads to less educational commitments (for native adolescents). Delinquency, albeit insignificant, has the expected sign in the migrant youth model.

Because some studies do find associations between neighbourhood affluence and ethnic concentration and educational outcomes, also for native youth samples (for reviews, see: Leventhal \& Brooks-Gunn, 2000; Nieuwenhuis \& Hooimeijer, 2013), we will examine if we can reproduce these results when not controlling for selection bias. For this purpose, we compare OLS models clustered on individuals, with FE models (Table 3). For migrant youth, the OLS model (Table 3: M1) shows that living in neighbourhoods with more than $20 \%$ nonWestern immigrants has a positive effect on the educational commitments, compared to living in neighbourhoods with less than $10 \%$ non-Western immigrants. We do not find a significant value for average property value. Comparing with the FE model (Table 3: M2), we see that the magnitude of the effect of the variable proportion of non-Western immigrants increase, besides, also the category $10-20 \%$ non-Western becomes significant. It is a function of FE models to control for time-invariant unmeasured characteristics that may, in our case, influence both neighbourhood selection and educational commitments. Apparently, for migrant youth, neighbourhood effects become more pronounced when controlling for such 
characteristics, suggesting that the findings of the OLS models are caused by neglecting to measure certain characteristics.

When looking at the models for native adolescents (Table 3: M3 and M4), we see that the OLS model suggests a relationship between the proportion of immigrants and average property value and educational commitments, however, they vanish when fitting a FE model. Besides, the magnitudes of the values of the statistically significant variables in the OLS model decrease drastically in the FE model. This finding supports the idea that the found neighbourhood effects in the OLS model are actually family effects, which disappear when controlling for any time-invariant unobserved (family) characteristics.

Both comparisons suggest selection bias. For migrant youth, OLS models seem to underestimate neighbourhood effects, while for native youth, OLS models seem to overestimate these effects. This is a strong argument to favour FE models over OLS models, and to some extent explains the difference between our findings and findings of other studies. It should be noted that the method only controls for time-invariant unobserved individual characteristics, and does not control for time-varying unobserved characteristics, so the presence of selection bias cannot be ruled out totally. However, that we are still able to find neighbourhood effects using this technique adds to the robustness of our findings.

Table 3: OLS vs. FE models on educational commitments: comparison of neighbourhood characteristics

\begin{tabular}{|c|c|c|c|c|}
\hline & \multicolumn{2}{|c|}{ Sample: migrant youth $(\mathrm{N}=406)$} & \multicolumn{2}{|c|}{ Sample: natives $(\mathrm{N}=3747)$} \\
\hline & M1: OLS & M2: FE & M3: OLS & M4: FE \\
\hline & coef. (s.e.) & coef. (s.e.) & coef. (s.e.) & coef. (s.e.) \\
\hline \multicolumn{5}{|c|}{ Prop. non-Western immigrants (ref.: <.10) } \\
\hline $.10-.20$ & $.362(.300)$ & $1.464(.391)^{* *}$ & $.021(065)$ & $-.115(.126)$ \\
\hline$>.20$ & $.689(.271)^{*}$ & $.925(.310)^{* *}$ & $.206(083)^{*}$ & $-.086(.115)$ \\
\hline Average property value & $-.111(.183)$ & $-.231(.180)$ & $.067(.022)^{* *}$ & $.002(.040)$ \\
\hline $\mathrm{R}^{2}$ & .2131 & .0997 & .0913 & .0419 \\
\hline $\mathrm{F}$ & $5.10 * *$ & $5.49 * *$ & $11.07 * *$ & $11.92 * *$ \\
\hline
\end{tabular}

\section{Conclusion and discussion}

We investigated the effect of two neighbourhood characteristics on educational commitments: immigrant concentrations and neighbourhood affluence. By employing separate analyses for migrant youth and native adolescents, we find that natives are not influenced by these neighbourhood characteristics, while migrant youth is clearly affected by the ethnic composition of the neighbourhood. The results indicate that, for migrant youth, living in neighbourhoods with $10-20 \%$ or more than $20 \%$ ethnic minorities increase their educational commitments compared to living in neighbourhoods with less than $10 \%$ ethnic minorities. Moreover, we find that neighbourhoods with 10-20\% ethnic minorities might be the most favourable, although the difference with more than $20 \%$ is only marginally significant. This 
finding brings together the two hypotheses we mentioned: the first hypothesis states that there is less native social capital and that there are less positive role models in ethnically concentrated neighbourhoods, hindering social mobility. The other hypothesis predicts that ethnic concentrations can lead to stronger ethnic social networks, enabling minorities to help each other out, therewith facilitating social mobility. Our findings suggest that moderate proportions of immigrants in the neighbourhood are most favourably for the development of adolescents' educational commitments, because in such neighbourhoods they can profit the most from on the one hand contact with natives, bridging the gap to the native society, and on the other hand contact with co-ethnics, giving access to ethnic support networks.

Furthermore, we find no relation between neighbourhood affluence and adolescents' educational commitments. In fact, the influence of the neighbourhood's immigrant concentration accounts for all of the neighbourhood's influence. This is interesting, because it suggests that the distribution of different ethnicities in the neighbourhood is more important than the distribution of different social classes. However, the ethnic population within a neighbourhood is often far from being homogeneous: the ethnic community within a neighbourhood might vary substantially in educational background. A larger proportion of higher educated ethnic minorities in the neighbourhood is found to be positively related to migrant youth's educational achievement (Cardak \& McDonald, 2004). In this sense, neighbourhood affluence might still have some influence on migrant youth's educational commitments, however, it might provide with better results when measured separately for the ethnic population.

After finding support for the influence of the neighbourhoods' ethnic concentrations on educational commitments, we wanted to test whether commonly unobserved characteristics of the research population might alter the relationship between neighbourhood characteristics and individual outcomes. We hypothesised that adolescents with a resilient personality can cope better with environmental stress and demands, and will therefore experience weaker effects of neighbourhood characteristics on their educational commitments than do adolescents without a resilient personality. Our findings show that resilients are not only influenced less by environmental disadvantage, but are influenced less in general by their surroundings, both positively and negatively. This indicates that resilients are more likely to develop their own value-orientations, despite outside pressures. The support we found for the neighbourhood's collective socialisation mechanism might thus only work for adolescents who are susceptible for socialisation. This is interesting, because personality theory assumes that resilients are better able to cope with stress and adversity, however, it seems that they are also less likely to take in positive environmental influences. Resilients seem to choose their own path amongst alternative commitments.

Our findings shine some interesting light on socialisation mechanisms in neighbourhoods. As mentioned in the introduction, neighbourhood research often takes educational achievement as an outcome, while implying that adolescents are socialised by neighbourhood adults into having certain educational commitments, which consequently influences their achievement. We show that it is indeed quite likely that educational commitments are influenced by neighbourhood characteristics, albeit differently for migrant youth and native adolescents. And other studies have showed that educational commitment is related to greater school performance (Germeijs \& Verschueren, 2007; Klimstra et al., 2012; 
Robbins et al., 2004). It is therefore very plausible that youth's educational commitments are socialised through neighbourhood characteristics, and consequently influencing their educational achievement. However, other studies have shown that, for migrant youth, educational commitments are not always translated into educational achievement, while for native youth this is more likely to be the case (Elffers \& Oort, 2013). It is likely that other factors also influence educational achievement for migrant youth, such as discrimination or stigmatisation, which dissolve the positive influence educational commitments might have. Interestingly enough, as they age, migrant youth might start to realise the lower returns they gain from educational commitments compared to native adolescents, since we find a negative relationship between age and educational commitment for migrant youth, while the relationship for natives is positive.

We try to overcome the problem of selection bias by employing fixed-effects models, which control for time-invariant unobserved individual characteristics. In our analyses, we find clear support for the hypothesis of selection bias. However, our respondents, adolescents, are not in the position to choose their own neighbourhood. This decision is made by their parents. This means we are possibly dealing with an intergenerational selection effect (see also van Ham et al. forthcoming). It is argued that neighbourhood effects are transmittable over generations, i.e., that parents are influenced by their own childhood neighbourhood, shaping their educational and occupational choices and thus influencing their resources later in life, including the resources available for their children and the neighbourhood in which they will raise their children (Sharkey \& Elwert, 2011). It is plausible that also neighbourhood selection effects are intergenerational transmittable: parents on the one hand choose the neighbourhood where they will raise their children and on the other hand influence their children's educational commitments. Considering these arguments, controlling for selection bias should dissolve any neighbourhood effects. This is true for native adolescents, but for migrant youth, we do find neighbourhood effects. Thus, our findings suggest such an intergenerational selection effect for native adolescents. For migrant youth, however, controlling for selection actually reveals the neighbourhood effects.

In the introduction, we made the point that unobserved heterogeneity might be the reason for the great variation in findings from the neighbourhood effects literature. We introduced two personal characteristics to look into this reasoning: a migration background and a resilient personality. The results clearly show that neighbourhood effects cannot be easily generalised. First, we do not find support for neighbourhood effects on native adolescents, however, we do find clear support that migrant youth's educational commitments are affected by the ethnic composition of the neighbourhood. And second, strong differences seem to exist between adolescents with a resilient personality and those without. The influence of the neighbourhood's ethnic composition on adolescents without a resilient personality is much stronger than for resilient adolescents. To sum this up, we would like to stress the importance of knowing the background of your research population when examining neighbourhood effects. Some people might be strongly influenced by their neighbourhood, while others are hardly susceptible for any environmental influences. 


\section{Acknowledgements}

We would like to thank David Manley, Rory Coulter and Dario Diodato for their valuable input in discussions about the modelling strategy used in this paper. Part of this research was financially supported by the EU (NBHCHOICE Career Integration Grant under FP7PEOPLE-2011-CIG).

\section{Literature}

Ainsworth, J. W. 2002. "Why does it take a village? The mediation of neighborhood effects on educational achievement.” Social Forces 81 (1): 117-152.

Akers, R. L., M. D. Krohn, L. Lanza-Kaduce, and M. Radosevich. 1979. "Social learning and deviant behavior: a specific test of a general theory.” American Sociological Review 44 (4): 636-655.

Allison, P. D. 2009. Fixed effects regression models. Thousand Oaks, CA: Sage.

Asendorpf, J. B., P. Borkenau, F. Ostendorf, and M. A. G. van Aken. 2001. „Carving personality description at its joints: Confirmation of three replicable personality prototypes for both children and adults.” European Journal of Personality 15: 169198.

Block, J. H. \& J. Block. 1980. "The role of ego-control and ego-resiliency in the organization of behavior.” In Development of cognition, affect, and social relations, edited by W. A. Collins, 39-101. Hillsdale: Lawrence Erlbaum Associates.

Bourdieu, P. 1986. "The forms of capital." In Handbook of theory of research for the sociology of education, edited by J. E. Richardson, 241-258. Westport, CT: Greenword Press.

Burt, R. S. 2001. "Structural holes versus network closure as social capital.” In Social capital: Theory and research, edited by N. Lin, K. Cook, and R. S. Burt, 31-56. New York: Aldine de Gruyter.

Cardak, B. A., and J. T. McDonald. 2004. "Neighbourhood effects, preference heterogeneity and immigrant educational attainment." Applied Economics 36 (6): 559-572.

Caspi, A. 1998. "Personality development across the life course." In Handbook of child psychology: Vol. 3. Social, emotional, and personality development, edited by W. Damon, and N. Eisenberg, 311-388. New York, NY: Wiley.

CBS. 2006. Kerncijfers postcodegebieden, 2004 [Key figures for postcode areas, 2004]. The Hague: Statistics Netherlands.

CBS. 2011. Kerncijfers postcodegebieden, 2008-2010 [Key figures for postcode areas, 20082010]. The Hague: Statistics Netherlands.

Coleman, J. S. 1988. "Social capital in the creation of human capital.” American Journal of Sociology, Supplement 94: S95-S120.

Crocetti, E., M. Rubini, and W. H. J. Meeus. 2008. "Capturing the dynamics of identity formation in various ethnic groups: Development and validation of a threedimensional model.” Journal of Adolescence 31: 207-222.

Dietz, R. D. 2002. "The estimation of neighborhood effects in the social sciences: An interdisciplinary approach.” Social Science Research 31: 539-575.

Downey, D. B., J. W. Ainsworth, and Z. Qian. 2009. "Rethinking the attitude-achievement paradox among blacks.” Sociology of Education 82: 1-19. 
Durlauf, S. N. 2004. "Neighbourhood effects." In Handbook of regional and urban economics Volume 4, Cities and Geography, edited by J. V. Henderson, and J. F. Thisse. Amsterdam: Elsevier.

Edens, J. F., T. A. Cavell, and J. N. Hughes. 1999. "The self-systems of aggressive children: a cluster-analytic investigation.” Journal of Child Psychology and Psychiatry 40: 441453.

Elffers, L., and F. J. Oort. 2013. “Great expectations: students' educational attitudes upon the transition to post-secondary vocational education.” Social Psychology of Education 16: $1-22$.

Ellen, I. G., and M. A. Turner. 1997. "Does neighbourhood matter? Assessing recent evidence.” Housing Policy Debate 8 (4): 833-866.

Furman, W., and D. Buhrmester. 1985. "Children's perceptions of the personal relationship in their social networks.” Developmental Psychology 21 (6): 1016-1024.

Galster, G. 2002. "An economic efficiency analysis of deconcentrating poverty populations.” Journal of Housing Economics 11 (4): 303-329.

Galster, G. C. 2008. "Quantifying the effect of neighbourhood on individuals: Challenges, alternative approaches, and promising directions.” Schmollers Jahrbuch 128: 1-42.

Galster, G. C. 2011. "The mechanism(s) of neighbourhood effects: Theory, evidence, and policy implications.” In Neighbourhood effects research: New perspectives, edited by M. van Ham, D. Manley, N. Bailey, L. Simpson, and D. Maclennan, 23-56. Dordrecht: Springer.

Germeijs, V., and K. Verschueren. 2007. "High school students' career decision-making process: Consequences for choice implementation in higher education." Journal of Vocational Behavior 70: 223-241.

Gerris, J. R. M., T. M. J. M. Houtmans, E. M. G. Kwaaitaal-Roosen, J. C. Schipper, A. A. Vermulst, and J. M. A. M. Janssens. 1998. Parents, adolescents and young adults in Dutch families: A longitudinal study. Nijmegen: Institute of Familiy Studies, University of Nijmegen.

Gibson, C. L. 2012. “An investigation of neighborhood disadvantage, low self-control, and violent victimization among youth.” Youth Violence and Juvenile Justice 10 (1): 4163.

Gijsberts, M., W. Huijnk, and J. Dagevos. 2012. Jaarrapport integratie 2011 [Integration report 2011]. The Hague: The Netherlands Institute for Social Research.

Goldberg, L. R. 1992. "The development of markers for the big-five factor structure." Psychological Assessment 4: 26-42.

Jones, S., and D. R. Lynam. 2009. "In the eye of the impulsive beholder: The interaction between impulsivity and perceived informal social control on offending." Criminal Justice and Behavior 36: 307-321.

Klimstra, T. A., W. W. Hale III, Q. A. W. Raaijmakers, S. J. T. Branje, and W. H. J. Meeus. 2010. “A developmental typology of adolescent personality." European Journal of Personality 24: 309-323.

Klimstra, T. A., K. Luyckx, V. Germeijs, W. H. J. Meeus, and L. Goossens. 2012. "Personality traits and educational identity formation in late adolescents: Longitudinal associations and academic progress.” Journal of Youth and Adolescence 41: 346-361. 
Lareau, A. 2003. Unequal childhoods. Class, race, and family life. Berkeley: University of California Press.

Laursen, B. 1993. "The perceived impact of conflict on adolescent relationships.” MerrillPalmer Quarterly 39: 535-550.

Leventhal, T., and Brooks-Gunn, J. 2000. "The neighborhoods they live in: The effects of neighborhood residence on child and adolescent outcomes.” Psychological Bulletin 126 (2): 309-337.

Lynam, D. R., A. Caspi, T. E. Moffit, P.-O. Wikström, R. Loeber, and S. Novak. 2000. “The interaction between impulsivity and neighborhood context on offending: The effects of impulsivity are stronger in poorer neighborhoods.” Journal of Abnormal Psychology 109 (4): 563-574.

MacLeod, J. 1987. Ain't no makin' it. Boulder, CO: Westview Press.

Martinovic, B., F. van Tubergen, and I. Maas. 2009. "Dynamics of interethnic contact: A panel study of immigrants in the Netherlands.” European Sociological Review 25 (3): 303-18.

Meeus, W., R. van de Schoot, T. Klimstra, and S. Branje. 2011. "Personality types in adolescence: Change and stability and links with adjustment and relationships: A fivewave longitudinal study.” Developmental Psychology 47: 1181-1195.

Meier, M. H, W. S. Slutske, S. Arndt, and R. J. Cadoret. 2008. "Impulsive and callous traits are more strongly associated with delinquent behavior in higher risk neighborhoods among boys and girls.” Journal of Abnormal Psychology 117 (2): 377-385.

Mollenhorst, G., B. Völker, and H. Flap. 2008. "Social contexts and personal relationships: The effect of meeting opportunities on similarity for relationships of different strength.” Social Networks 30: 60-68.

Nieuwenhuis, J., and P. Hooimeijer. 2013. "The association between neighbourhoods and educational achievement, a systematic review and meta-analysis.” Unpublished manuscript, Utrecht University, Utrecht.

Nieuwenhuis, J., P. Hooimeijer, and W. Meeus. 2013. "Neighbourhood effects on educational attainment of adolescents, buffered by personality and educational commitment.” Unpublished manuscript, Utrecht University, Utrecht.

Pásztor, A. 2010. “'Go, go on and go higher an’ higher’. Second-generation Turks' understanding of the role of education and their struggle through the Dutch school system.” British Journal of Sociology of Education 31 (1): 59-70.

Portes, A., and D. MacLeod. 1999. "Educating the second generation: determinants of academic achievement among children of immigrants in the United States.” Journal of Ethnic and Migration Studies 25 (3): 373-396.

Putnam, R. D. 2000. Bowling alone. New York: Simon \& Schuster.

Robbins, S. B., K. Lauver, H. Le, D. Davis, R. Langley, and A. Carlstrom. 2004. "Do psychosocial and study skill factors predict college outcomes? A meta-analysis.” Psychological Bulletin 130 (2): 261-288.

Robins, R. W., O. P. John, A. Caspi, T. E. Moffitt, and M. Stouthamer-Loeber. 1996. "Resilient, overcontrolled, and undercontrolled boys: Three replicable personality types.” Journal of Personality and Social Psychology 70: 157-171. 
Sampson, R. J., and S. W. Raudenbush. 1999. "Systematic social observation of public spaces: A new look at disorder in urban neighborhoods." American Journal of Sociology 105 (3): 603-651.

Sharkey, P., and F. Elwert. 2011. "The legacy of disadvantage: Multigenerational neighborhood effects on cognitive ability.” American Journal of Sociology 116 (6): 1934-1981.

van Ham, M., D. Manley, N. Bailey, L. Simpson, and D. Maclennan. 2012. "New perspectives.” In Neighbourhood effects research: New perspectives, edited by M. van Ham, D. Manley, N. Bailey, L. Simpson, D. Maclennan, 1-22. Dordrecht: Springer.

van Ham, M., D. Manley D., N. Bailey, L. Simpson, and D. Maclennan. 2013. "Understanding neighbourhood dynamics." In Understanding neighbourhood dynamics: New insights for neighbourhood effects research, edited by M. van Ham, D. Manley, N. Bailey, L. Simpson, and D. Maclennan, 1-21. Dordrecht: Springer.

van Ham M., L. Hedman, D. Manley, R. Coulter, and J. Östh. Forthcoming. "Intergenerational transmission of neighbourhood poverty. An analysis of neighbourhood histories of individuals." Transactions of the Institute of British Geographers.

Wilson, W. J. 1996. When work disappears. New York, NY: Knopf.

Zalot, A, D. J. Jones, C. Kincaid, and T. Smith. 2009. "Hyperactivity, impulsivity, inattention (HIA) and conduct problems among African American youth: The roles of neighborhood and gender.” Journal of Abnormal Child Psychology 37: 535-549.

Zhou, M. 2009. "How Neighbourhoods Matter for Immigrant Children: The Formation of Educational Resources in Chinatown, Koreatown and Pico Union, Los Angeles.” Journal of Ethnic and Migration Studies 35 (7): 1153-1179.

Zhou, M., and C. L. Bankston. 1998. Growing up American. How Vietnamese children adapt to life in the US. New York: Russell Sage Foundation.

Zimmerman, G. M. 2010. "Impulsivity, offending, and the neighborhood: Investigating the person-context nexus.” Journal of Quantitative Criminology 26: 301-332. 